\title{
Molecular Alterations Associated with Osteosarcoma Development
}

\author{
Kosei Ando, ${ }^{1,2,3}$ Kanji Mori, ${ }^{4}$ Franck Verrecchia, ${ }^{1,2}$ Baud'huin Marc, 1, 2,5 \\ Françoise Rédini, 1, 2, 3,5 and Dominique Heymann' 1, 2,3,5 \\ ${ }^{1}$ INSERM, UMR-S 957, 1 Rue Gaston Veil, 44035 Nantes, France \\ ${ }^{2}$ Physiopathologie de la Résorption Osseuse et Thérapie des Tumeurs Osseuses Primitives, Université de Nantes, \\ Nantes Atlantique Universités, EA3822, 1 Rue Gaston Veil, 44035 Nantes, France \\ ${ }^{3}$ Equipe Labellisée Ligue 2012, Nantes, France \\ ${ }^{4}$ Department of Orthopaedic Surgery, Shiga University of Medical Science, Tsukinowa-cho, Seta, Otsu, Shiga 520-2192, Japan \\ ${ }^{5}$ Nantes University Hospital, Nantes, France
}

Correspondence should be addressed to Kosei Ando, andok.ercgv@gmail.com

Received 30 September 2011; Accepted 2 December 2011

Academic Editor: Chandrajit Premanand Raut

Copyright (c) 2012 Kosei Ando et al. This is an open access article distributed under the Creative Commons Attribution License, which permits unrestricted use, distribution, and reproduction in any medium, provided the original work is properly cited.

\begin{abstract}
Osteosarcoma is the most frequent malignant primary bone tumor characterized by a high potency to form lung metastases which is the main cause of death. Unfortunately, the conventional chemotherapy is not fully effective on osteosarcoma metastases. The progression of a primary tumor to metastasis requires multiple processes, which are neovascularization, proliferation, invasion, survival in the bloodstream, apoptosis resistance, arrest at a distant organ, and outgrowth in secondary sites. Consequently, recent studies have revealed new insights into the molecular mechanisms of metastasis development. The understanding of the mechanism of molecular alterations can provide the identification of novel therapeutic targets and/or prognostic markers for osteosarcoma treatment to improve the clinical outcome.
\end{abstract}

\section{Introduction}

Osteosarcoma (OS) most often occurs, during childhood and adolescence, in the metaphysis of long bones, including large growth plates with high proliferation activity and bone turnover [1]. Historically, patients with primary OS have been treated with resection surgery alone, resulting in poor prognosis. Clinical outcome of localized OS has improved with neoadjuvant chemotherapies, based on methotrexate, cisplatin, doxorubicin, and ifosfamide treatments. The 5-year survival has indeed increased to around $60 \%$. However, the 5 -year survival of patients with OS metastasis still remains about 30\% [2-7]. OS metastases appear most frequently in the lung [8] and are the main cause of death for patients with OS, because micrometastases are undetectable at initial diagnosis $[9,10]$. Taken together, OS patients with metastases present further worse clinical results than those without metastases. Thus, more effective treatments and/or a more personalized therapy (i.e., treatments according to specific genes or protein profile expressions) are needed for patients with OS associated with pulmonary metastases.

The establishment of cancer metastasis involves several complex steps: intravasation, survival in the circulation, arrest at a distant organ, extravasation, and growth in secondary sites (Figure 1). Molecular alterations of these steps have been practically analyzed. The understanding of metastasis mechanism might allow us to find new molecular targets for improvement of the patients' survival. This paper describes the molecular factors associated with OS development and summarizes the main molecular alterations involved in this bone disease, especially in metastatic OS, which strongly contribute to the development of novel therapeutic approaches. 


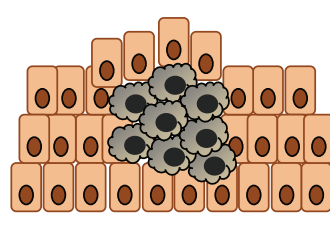

Proliferation IGF-I, GH

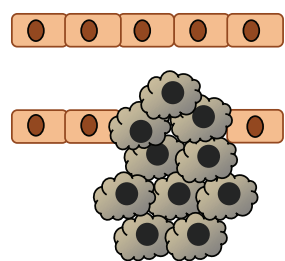

Proliferation in the secondary site IGF-I, GH
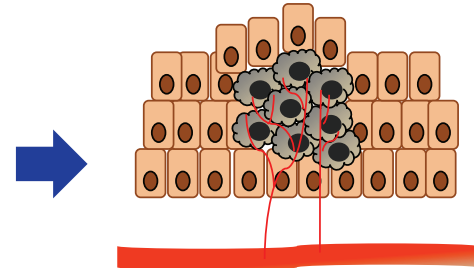

Neovascularization VEGF, TGF- $\beta$, PDGF, bFGF, MMP-9, angiostatin, endostatin
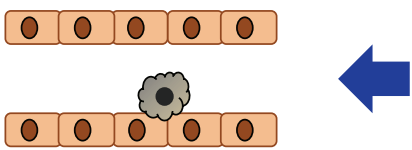
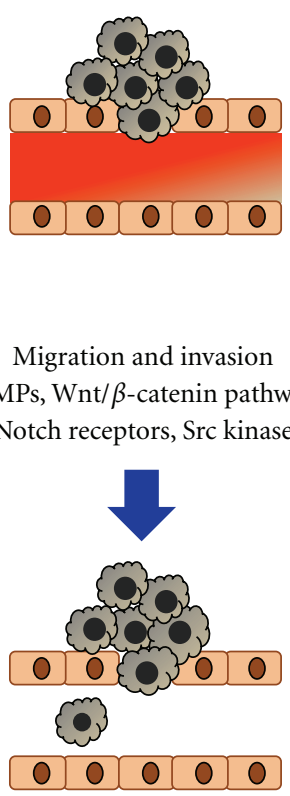

Migration and invasion MMPs, Wnt/ $\beta$-catenin pathway, Notch receptors, Src kinase

$$
\begin{gathered}
\text { Intravasation and } \\
\text { anoikis resistance } \\
\text { Src/PI3K/Aktpathway, } \\
\text { integrin, Bcl-2, Caveolin-1 }
\end{gathered}
$$

FIGURE 1: The main steps of the tumor metastatic process. Tumor cells proliferate at the primary site and neovascularization is induced by tumor environment such as hypoxia. In turn, they migrate and invade into the bloodstream. These tumor cells in the circulation need to survive against anoikis to arrest in a distant organ. Metastatic colonization at the secondary site involves the interactions between tumor cells and the microenvironment.

\section{Neovascularization is a Key Parameter in Osteosarcoma Growth}

Nutriments and oxygen required for the metabolism of normal and tumor cells are delivered by blood vessels. Neoformation of blood vessels allows growth, invasion, and metastatic spread of cancer cells in malignant pathologies. [11, 12 ]. The process of neovascularization is generally regulated by a balance between angiogenic inducers and inhibitors. The shift in favor of angiogenic inducers, known as the "angiogenic switch," promotes the formation of a new blood supply enhancing tumor growth and metastasis. Neovascularization is induced by the tumor environment such as hypoxia, acidosis, or inflammation in an oncologic context. In these conditions, both tumor cells and host endothelial cells can increase the expression of proangiogenic: vascular endothelial growth factor (VEGF), platelet-derived growth factor (PDGF), basic fibroblast growth factor (bFGF), and transforming growth factor $($ TGF- $\beta$ ) [13-17]. Tumor cells also secrete proteolytic enzymes such as matrix metalloproteinases (MMPs), which degrade basement membrane and extracellular matrix (ECM) promoting cell dissemination [18, 19]. MMP-9 is indeed highly related to the angiogenic switch because it can activate proangiogenic factors $[20,21]$. Several studies have demonstrated that VEGF or TGF- $\beta$ expression is associated with an increase of tumor vascularity, invasion, and poor prognosis in OS [22-24]. It has been shown that high serumVEGF levels in OS correlate with tumor progression, metastasis, and poor prognosis $[25,26]$. However, the relationship between an increase of tumor vascularity and a poor prognosis is controversial in OS [27-29].

The well-known angiogenic inhibitors are angiostatin and endostatin. Angiostatin is a cleavage product of plasminogen [30], whereas endostatin is the carboxyl-terminal fragment of collagen XVIII [31]. They inhibit endothelial cell proliferation and migration [32]. The resulting antiangiogenic activity has been demonstrated in various tumor models in vivo [33-38]. Based on these (pre)clinical results, clinical trials are currently running to evaluate the effect of human recombinant endostatin. Although showed a well tolerability and safety in patients with malignant solid tumors, it induces a minor antitumor effect not related to the vascular changes [39-41]. Inhibition of neovascularization should suppress tumor growth despite tumor cell heterogeneity because blood supply is necessary for all tumors to survive. Furthermore, the available data from animal models and phase I and II clinical trials of angiostatin and endostatin have shown that these agents are well-tolerated at therapeutic doses: $15-600 \mathrm{mg} / \mathrm{m}^{2} /$ day added to those patients, although the use of antiangiogenic therapy has raised the debate about interference with normal physiological processes such as wound healing and tissue repair [31,39-43]. 


\section{Migration and Invasion: Two Potential Therapeutic Targets}

Tumor migration and invasion through the ECM are critical in metastatic dissemination $[15,16]$. Degradation of the ECM, which leads to migration, invasion, and metastasis, releases MMPs (MMP-2 and MMP-9, in particular) and mcalpain in OS [44-46]. In addition, the Wnt/ $\beta$-catenin, Srckinase and Notch signaling pathways are also involved in migration and invasion [47-55].

MMPs are a family of zinc endopeptidases consisting of at least 20 different members and regulate different cellular metabolic processes $[56,57]$. They induce a variety of biological effects including growth, morphogenesis, apoptosis, tissue destruction, and cancer formation [58, 59]. Recently, bisphosphonates have been shown to downregulate MMPs expression and reduce the invasive potency of OS cells [6064]. Disulfiram is also able to control the invasion and metastasis in human OS cells through the MMP-2 and MMP-9 inhibition [65]. Both of m-calpain expression and MMP-2 secretion are inhibited by a siRNA targeting $\mathrm{m}$-calpain in SAOS-2 cells [46]. $\mathrm{m}$-calpain is also essential in the invasion and human OS metastasis [46]. These agents related to proteases represent new therapeutic targets and approaches to decrease the OS migration and invasion.

Wnt signaling pathway coordinates osteoblast proliferation and differentiation [66]. Disruptions in various components of the Wnt pathway result in disordered bone development and homeostasis [67]. The $\beta$-catenin-dependent Wnt signaling pathway is regulated by secreted Wnt antagonists divided into two groups. Wnt inhibitory factor 1 (WIF-1) and the secreted frizzled-related protein family directly bind to Wnt ligands while the Dickkopf families and sclerostin are blocking Wnt receptors trough the endocytosis of lowdensity lipoprotein receptor-related protein $5 / 6$ coreceptors [68-71]. This Wnt binding leads to the activation of disheveled, which in turn, releases $\beta$-catenin from the axinadenomatous polyposis coli-glycogen synthase kinase- $3 \beta$ complex, causing stabilization and accumulation of $\beta$-catenin in the cytoplasm. After its translocation to the nucleus, $\beta$-catenin binds to the T-cell factor/lymphocyte enhancer factor family of transcription factors and promotes downstream target oncogenes such as c-myc, cyclin D, survivin, and MMPs. These mechanisms are involved in proliferation, invasion, and metastasis in various human cancers [7275]. OS frequently expresses high levels of cytoplasmic and/or nuclear $\beta$-catenin [76], which is also associated with metastasis $[77,78]$. These findings suggest that aberrant Wnt activation is crucial in multiple cancers, including OS [7981]. A preclinical study has demonstrated that the inhibition of Wnt $/ \beta$-catenin pathway induced lower levels of nuclear $\beta$-catenin, resulting in downregulation of the $\beta$-catenintargeted genes such as MMP-9, cyclin-D, c-myc, and survivin [82]. Several reports have demonstrated that WIF-1 silencing due to hypermethylation results in Wnt signaling activation in a variety of cancer. WIF-1 can inhibit the cell growth of those cancer cells $[79,80,83-86]$. The downregulation of WIF-1 expression plays a role in OS progression. Reexpression of WIF-1 also suppressed Wnt signaling pathway, resulting in the tumor growth and lung metastasis in vivo in OS mouse models [50]. These results indicate that WIF-1 can be a therapeutic agent against OS metastasis. However, the function of Wnt antagonists including WIF-1 is still unclear and further investigations are needed.

Notch signaling regulates development of many tissues and cell types through diverse effects on cell fate decision, stem cell renewal, differentiation, survival, and proliferation [87]. Notch signaling is one of several evolutionarily conserved signaling pathways in the development of multicellular organisms. Its temporal-spatial expression effects can specify diverse cellular events, including proliferation, differentiation, apoptosis, and stem cell maintenance. In mammals, there are four Notch receptors: Notch1-4, and eleven ligands [88]. The first targets of Notch are two basic helix-loop-helix transcriptional repressor families: the Hairy/enhancer-of-split (Hes) and the Hes with YRWP motif families [89]. Notch has been considered as a promoter of invasion in OS. The Notch receptor 1, 2, and Hes1 genes induced by Notch increase in highly metastatic OS. The Hes1 gene was inversely associated with the survival rate in human OS [52-55]. The OS cell invasion was reduced by an inhibition of the Notch signaling pathway whereas the cell proliferation was not blocked in a preclinical setting. The Notch-inhibited cells were less able to induce lung metastases in an orthotopic mouse than the negative controls. However, the mechanism in the inhibition of the Notch pathway and the downregulation of invasion resulted from Hes1 remains not clear $[53,55]$.

Src is a nonreceptor tyrosine kinase and encoded by the c-Src as a protooncogene. Src kinase activity is regulated by several receptor tyrosine kinases (RTKs) such as epidermal growth factor (EGF) RTK, PDGF-RTK, and integrin receptors [90-92]. Src family kinases are critical in the metastatic dissemination, such as cell proliferation, adhesion, invasion, survival, and angiogenesis. Either overexpression or activation of c-Src has been shown to occur in cancer development [49]. Src, involved in tumor metastasis widely, could be a novel therapeutic target in OS metastasis. Dasatinib, known as a Src kinase inhibitor, suppresses Bcr-Abl tyrosine kinase. The effect and safety of dasatinib have been established as therapeutic agent for imatinib-resistant chronic myelogenous leukemia in early-phase clinical trials. Also, several studies have shown that the dasatinib acts against Bcr-Ablpositive leukemic cell lines as well as other malignancies. The c-Src-mediated signaling pathways, related to tumor proliferation, adhesion, or migration, have been shown in various malignancies such as prostate cancer, lung cancer, and sarcoma [93-95]. In preclinical studies, dasatinib suppressed tumor migration and invasion with inhibition of the Src kinase activity and its downstream signaling in OS cell lines in vitro $[48,96]$. On the other hand, dasatinib had no effect on pulmonary metastases in vivo [48]. At present, the other specific Src kinase inhibitor, called saracatinib, is under investigation in phase II clinical trial of OS lung metastases (clinicaltrials.gov/ct2/show/NCT00752206). 


\section{Apoptosis Resistance and OS Progression}

Apoptosis is involved in cell survival in cancer metastasis through the all stages via two pathways. The first one is regulated by a death-receptor-bound to Fas or tumor-necrosis factor (TNF) family member, death-inducing signaling complex, and caspase- 8 . The second one is associated with p53, Bcl2 family member, cytochrome-c, and caspase-9. When caspase- 8 or -9 is activated, caspases of the downstream can be cleaved inducing cell death. Fas and its ligand (FasL) belong to the TNF death receptor superfamily and regulate tumorigenesis in a variety of primary malignancies and metastases [97-99]. Fas/FasL complex, constitutively expressed in lung tissue, enhances the Fas-apoptosis pathway and leads to cell death $[100,101]$. Fas receptor has been well known as a death receptor mediated apoptosis in a variety of tumor cells. Recent studies have revealed that Fas is also proapoptotic related to tumor proliferation, differentiation, and migration [102-104]. Thus, apoptosis resistance is crucial for establishment of tumor metastasis; it is implicated in treatment resistance with cancer metastasis [105]. Fas expression is often decreased in OS lung metastasis, whereas it is highly expressed in the primary tumors $[100,101,106]$. Furthermore, Fas-negative expressions correlate with tumor development and poor prognosis [100, 101, 107-109]. Inhibition of Fas signaling and/or the loss of FasL can develop the proliferation of Fas-positive OS cells in the lungs and can promote the growth of lung metastases in OS models in vivo [107].

Interleukin- (IL-) 12 increased the expressions of Fas receptor in OS lung metastasis through stimulation of the Fas promoter activity. In turn, the metastatic cells acquired the susceptibility to FasL in relation to Fas-induced apoptosis in the lung microenvironment [110]. In vivo, combination therapy of IL-12 with ifosfamide induces FasL expression, increasing the therapeutic efficacy via the Fas/FasL pathway [111]. Muramyl tripeptide phosphatidyl ethanolamine (MTP-PE) induces IL-12 production in OS patients through activation of macrophages $[1,112]$. MTP-PE also upregulates Fas expression when exogenous IL-12 is administered to the patients [106]. The combination of MTPPE with ifosfamide induces IL-12 and FasL, respectively, consequently the clinical outcome of the treated patients can be improved through the activation of tumor apoptosis [106]. These results suggest that Fas death receptor pathway may enhance the efficacy of chemotherapy in OS.

IL-18, which is an interferon- $\gamma$-inducing factor [113], affects an antitumor effect via the activation of natural killer (NK) cells or cytotoxic T cells $[113,114]$, inhibition of angiogenesis [115] and induction of FasL on Fas-positive tumor cells [116]. IL-18 has been shown to inhibit metastasis in OS cells through the activation of T-cells and NK-cells and the induction of the FasL expression [117]. In addition, the combination of ifosfamide with IL-18 suppresses the development of OS lung metastasis [118]. Taken together, Fas death receptor pathway is essential in the establishment of OS lung metastasis, and it may be a novel therapeutic target. However, the molecular mechanism of the loss of Fasmediated apoptosis in OS metastases is unknown.

\section{Survival in the Blood Circulation: Anoikis Resistance}

Cancer metastases require the anoikis-resisted cells to survive in the circulation. Anoikis, Greek for "homelessness," regulates cell homeostasis in tissues. Normal epithelial cells become apoptotic when exposed to anchorage-independent environments $[119,120]$. In turn, once tumor cells have entered into the bloodstream to disseminate distantly, the cellcell adhesions or ECM attachments are lost, which results in the specific apoptosis called anoikis [121]. Therefore, metastatic cells need to acquire the resistance to anoikis to survive during dissemination and colonization of secondary distant sites in the circulation.

Acquisition of anoikis resistance has been described in nonepithelial malignancies such as OS [122]. Many studies demonstrated the survival mechanism of cancer cells in the evasion of anoikis with various means such as Src/PI3K/Akt pathway, focal adhesion kinase, or Bcl-2 [123, 124]. Several studies have shown that $\beta 4$ integrin expression is involved in cancer progression [125-127]. The $\beta 4$ integrin expression is also implicated in the survival of OS cells in the circulation, because knockdown of $\beta 4$ integrin suppressed the cellproliferation under anchorage-independent sites in OS cells [128]. In addition, the knockdown of $\beta 4$ integrin in a mouse model inhibited lung metastases, and $\beta 4$ integrin-ezrin interaction appears to be essential for $\beta 4$ integrin expression. However, the relation between ezrin and $\beta 4$ integrin is still unknown [128]. Cell-cell adhesions can activate integrin signaling in anchorage-independent conditions and integrin expression patterns may contribute to the resistance to anoikis [129].

Switch from $\alpha_{V} \beta_{5}$ to $\alpha_{V} \beta_{6}$ integrin may suppress anoikis in squamous cell carcinoma cells through the activation of PI3K/Akt signaling pathway [130]. The PI3K/Akt pathway, which depends on Src kinase activation, is important for human OS cells to avoid anoikis [47]. Src has another role related to anoikis resistance with caveolin-1 in OS cells. Caveolin-1 is the major protein component of caveolae [131], which regulates several intracellular signaling pathways [132]. Caveolin-1 is highly expressed in osteoblasts [133] and its overexpression in OS cells inhibited anchorageindependent growth, invasion, and migration by blocking cSrc and c-Met tyrosine kinases in vitro [134]. In addition, Caveolin-1 overexpression suppressed the OS metastasis in vivo [134].

\section{Arrest and Extravasation: Final Step of Cell Migration}

The mechanism of migration arrest of metastatic cells is controversial. Metastatic tumor cells are generally thought to be trapped in the microcirculation because their size is larger than that of normal cells [135]. When the tumor cells in the bloodstream are trapped, microembolisms are structured, and the interaction with the local microenvironment begins consequently. Interestingly, cancer cells have the tendency to prefer a specific target organ in metastasis processes: Over $80 \%$ of all metastases in OS occur in the lungs [136]. 
This result suggests that circulating tumor cells can select their optimal sites to survive and grow via interactions with distinct molecules expressed on the endothelial cells in the distant organs [16]. In the circulation, cell colonization in the distant organs is mediated through the secretion of chemokines and proteinases, involved in extravasations [15, 16]. Recently, chemokines are regarded as important factors to control a site specificity of cancer metastasis including OSlung relation [137-140]. C-X-C-motif chemokine receptor 4 (CXCR4) and its ligand C-X-C-motif chemokine ligand 12 (CXCL12) have been shown to regulate an organ-specific metastasis by the formation of chemotactic gradients in several cancer [141-143]. Binding of CXCR4 to CXCL12 allows adhesion and extravasation of OS cells in pulmonary metastasis $[138,139,144,145]$. These results suggest that abundant expressions of CXCL12 in the lung may be involved in the high frequency of pulmonary metastases in OS. Highly CXCR4 expressions in OS-patient samples adversely correlated to event-free, overall, and metastasis-free survival [138]. These data suggest that CXCR4 could be useful as a prognostic factor in OS metastasis.

CXCR3, another chemokine receptor, has been identified in a variety of malignancies including OS [138, 146-148]. Its ligands, CXCL9, 10, and 11, are expressed in lungs. The inhibition of CXCR3 chemokine pathway down regulates the growth of OS lung metastasis. Recent study has demonstrated that CXCR3 inhibitor decreased the proliferation, survival and invasion of the tumor cells in an animal model of OS lung metastasis. In other words, the interaction between CXCR3 and its ligands can directly enhance the invasion, survival, and proliferation of tumor cells in the metastatic organ. This result suggests that targeting CXCR3 can specifically inhibit OS lung metastasis [144].

\section{Adhesion Step in the Metastatic Process}

Establishment at a distant organ requires that the metastatic cell connects to its new environment and re-establishes cell-cell adhesions. Ezrin is a membrane-cytoskeleton linker protein that acts as membrane organizers and linkers between plasma membrane and cytoskeleton controlling cellmicroenvironment and cell-cell interactions [149]. In addition, ezrin associates with several signaling transductions, such as Rho and PI3K/Akt pathways [150, 151]. Recently, high level expression of ezrin protein is correlated to metastasis in several cancers [152-154] as well as OS $[155,156]$. High expression of ezrin is associated with pulmonary metastasis in animal models $[155,157]$, and with poor outcome in pediatric OS patients [155]. Phosphorylated ezrin was shown to express at just early phase in lung metastasis [155] whereas it was dynamically expressed at both the early and late time point [156].

Sorafenib is a multipotent drug, and several molecular targets of sorafenib such as Raf kinases are implicated in OS development $[158,159]$. Recent preclinical study has reported that sorafenib suppressed the development of lung metastases via downregulation of ezrin-activated mitogenactivated protein kinase (MAPK)/Akt signaling [160]. In addition, sorafenib could induce apoptosis through a decrease of expression of the antiapoptotic Bcl-2 family [160]. These data suggest sorafenib may be a novel potential therapeutic option in patients with OS metastasis.

\section{Main Signaling Pathways Involved in Proliferation of Metastatic OS}

OS pathogenesis is clearly related with bone growth during adolescence, suggesting a potential relationship with higher expression of hormone levels $[161,162]$. Thus, several studies have suggested that molecular alterations in the growth hormone (GH)/insulin-like growth factor I (IGF-I) signaling pathways could lead to OS development in vitro and in vivo $[163,164]$. OS cells show both IGF-I and IGF-I receptor expression and highly response to IGF-I in vitro [164]. Serum IGF-I levels in mice with hypophysectomy are significantly downregulated, which is decreasing tumor growth and development of metastasis [165].

A phase I trial in patients with metastatic and/or recurrent OS was performed with somatostatin analog (OncoLar) to reduce serum IGF-I [166]. In this trial, OncoLar treatment in 21 OS patients resulted in a $46 \%$ decrease in serum IGFI levels without toxicity. In a preclinical study conducted on dogs with naturally occurring OS, OncoLar [167] reduced serum IGF-I levels were by approximately $43 \%$ without toxicity. However, no difference in primary tumor necrosis, apoptosis, or survival was observed in dogs treated with a combination of OncoLar and chemotherapy in comparison with just chemotherapy. These observations indicate that the extent or duration of serum IGF-I suppression induced by OncoLar was not enough to improve a clinical outcome. IGF-I receptor (IGF-IR) axis is also implicated in OS development; inhibition of IGF-IR could inhibit tumor growth, activate apoptosis and up-regulate the chemosensitivity and radiosensitivity in OS cells $[168,169]$.

Recently, human monoclonal antibodies targeting the IGF-IR were tested in both preclinical and clinical studies. Inhibition of IGF-IR with some monoclonal antibodies enhances the antitumor effects in several OS xenograft models $[170,171]$. More recently, a clinical study has demonstrated that high IGF-IR expression is a poor prognostic factor for OS patients leading to OS development and metastasis [172]. Thus, IGF-IR targeting therapy can be a novel strategy for the treatment of OS associated with metastasis.

\section{Dormancy}

Unfortunately, tumor metastasis occasionally occurs for patients with malignancies a long time after the success of primary therapy $[173,174]$. This latency period is generally the result of tumor dormancy, which is frequently asymptomatic and clinically undetectable for months or years until relapse. Once tumor cells are settled in a secondary site, they can grow, die by apoptosis, or remain dormant. Two ways of tumor dormancy have been described, (i) tumor mass dormancy (dormant micrometastases) and (ii) cellular dormancy [174-176]. In dormant micrometastases, tumor 


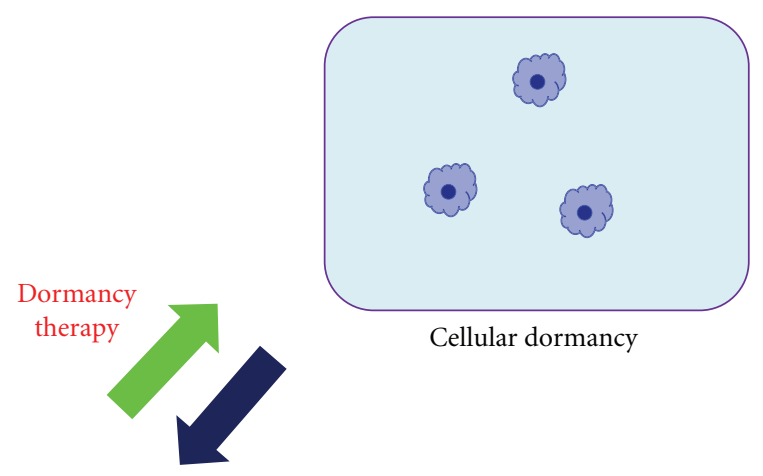

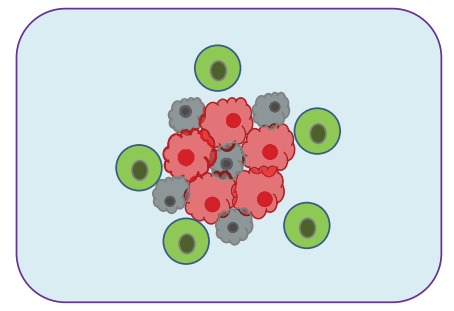

Dormant micrometastases Balancing between apoptosis and mitosis Balanced by immune system

Single tumor cell

Activated tumor cell
Angiogenic switch

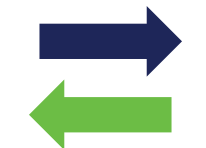

Dormancy therapy

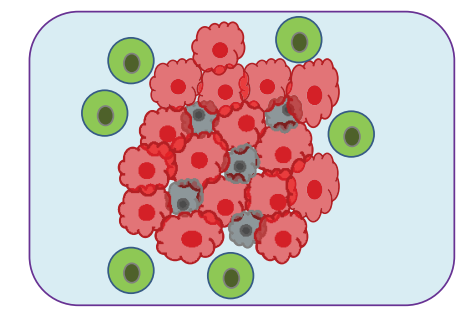

Micrometastases development

Apoptotic cell

Lymphocyte

FIGURE 2: Tumor metastasis dormancy is associated with the risk of recurrence of OS and late development of lung metastases. Tumor dormancy is thought to consist of tumor mass dormancy (dormant micrometastases) and cellular dormancy. In tumor mass dormancy (dormant micrometastases), tumor cells generally divide but not in cellular dormancy. The tumor growth is strictly limited by the lack of blood supply or immune system. Dormant state of micrometastases is involved in angiogenic switch and/or the adaptive immune system. Dormancy therapy could contribute to improve the treatment of patients with cancer.

cells generally divide but the growth is limited. Cellular dormancy (dormant single tumor cell) can occur when tumor cells enter in a quiescence state and do not divide any more. Tumor cells in dormancy are usually resistant to conventional drug because current treatments target cells in division. However, the mechanisms allowing dormant tumor cells to survive to conventional chemotherapies and then resume the tumor outgrowth remain unknown.

Dormant micrometastases are thought to be present under a balance between cell proliferation and apoptosis $[176,177]$. Dormant state of micrometastases is involved in lack of nutrition and oxygen from vasculature in relation to angiogenic switch and/or the adaptive immune system [178-182]. Endothelial cells in the microenvironment can enhance dormant tumor cells via cell-to-cell interactions and induction of angiogenesis [180]. The ECM also plays an important role in activation of dormant cells. When tumor cells fail to adhere to the ECM, they may enter in dormancy. It has been postulated that micrometastases fail to properly connect to the ECM and survive in the dormant state because they are deprived of growth factors and angiogenic signaling. Adhesion to the ECM could induce tumor cells to switch a dormancy state to a proliferation state via integrin signaling [181]. On the other hand, both tumor cells and host stromal cells modulate the microenvironment such as ECM and vascular walls. Those mechanisms may regulate the maintenance in dormancy or the activation metastatic growth for a single tumor cell or micrometastases respectively (Figure 2) $[17,181]$.

In vivo molecular mechanisms of a variety of cancers including OS in dormant state have been assessed with genome transcriptional analysis [181]. This study suggests that antiangiogenic proteins such as angiomotin, which has been shown to suppress tumor growth and keep dormancy of tumor metastases [179], are upregulated during dormancy. Thus, the tumor proliferation and invasion are inhibited under preangiogenic state. Tumor cells in proliferation state also increased the key cancer pathways such as EGF receptor1, IGF-IR, and PI3K. The mechanism of regulating tumor dormancy is unknown in OS. However, if it is possible to induce and/or keep in a dormant state or to induce cell death in residual dormant cells by targeting their survival and drug resistance mechanisms, the treatment for the patients with OS may be further improved.

\section{Conclusion}

OS associated with metastases still have poor clinical outcome, and conventional therapies are not fully effective. In addition, clinical output of novel available chemotherapeutic 
approaches is still unclear. Recent studies have disclosed new insights into the molecular mechanisms of metastasis as above mentioned. However, much more unknown questions remain; determinant factors of selective colonization in different organs, the mechanisms of tumor dormancy, and the mechanisms of metastasis suppressors, and so forth. Thus, future research critically needs to be directed towards identifying the molecular alterations in OS microenvironments.

\section{Acknowledgment}

Dr. K. Ando received a postdoctoral fellowship from the Région des Pays de La Loire (France).

\section{References}

[1] P. A. Meyers and R. Gorlick, "Osteosarcoma," Pediatric Clinics of North America, vol. 44, no. 4, pp. 973-989, 1997.

[2] G. Rosen, B. Caparros, and A. G. Huvos, "Preoperative chemotherapy for osteogenic sarcoma: selection of postoperative adjuvant chemotherapy based on the response of the primary tumor to preoperative chemotherapy," Cancer, vol. 49, no. 6, pp. 1221-1230, 1982.

[3] G. Bacci, A. Longhi, M. Cesari, M. Versari, and F. Bertoni, "Influence of local recurrence on survival in patients with extremity osteosarcoma treated with neoadjuvant chemotherapy: the experience of a single institution with 44 patients," Cancer, vol. 106, no. 12, pp. 2701-2706, 2006.

[4] O. S. Bruland and A. Pihl, "On the current management of osteosarcoma. A critical evaluation and a proposal for a modified treatment strategy," European Journal of Cancer, vol. 33, no. 11, pp. 1725-1731, 1997.

[5] A. Longhi, C. Errani, M. De Paolis, M. Mercuri, and G. Bacci, "Primary bone osteosarcoma in the pediatric age: state of the art," Cancer Treatment Reviews, vol. 32, no. 6, pp. 423-436, 2006.

[6] D. Heymann and F. Rédini, "Bone sarcomas: pathogenesis and new therapeutic approaches," IBMS, vol. 8, no. 9, pp. 402-414, 2011.

[7] D. Heymann, Ed., Bone cancer: progression and therapeutic approaches, Academic Press, 2010.

[8] G. Bacci, S. Ferrari, A. Longhi et al., "Pattern of relapse in patients with osteosarcoma of the extremities treated with neoadjuvant chemotherapy," European Journal of Cancer, vol. 37, no. 1, pp. 32-38, 2001.

[9] D. Dunn and L. P. Dehner, "Metastatic osteosarcoma to lung: a clinicopathologic study of surgical biopsies and resections," Cancer, vol. 40, no. 6, pp. 3054-3064, 1977.

[10] W. F. Enneking, S. S. Spanier, and M. A. Goodman, "A system for the surgical staging of musculoskeletal sarcoma," Clinical Orthopaedics and Related Research, vol. 153, pp. 106-120, 1980.

[11] J. Folkman, "The role of angiogenesis in tumor growth," Seminars in Cancer Biology, vol. 3, no. 2, pp. 65-71, 1992.

[12] W. D. Thompson, K. J. Shiach, and R. A. Fraser, "Tumours acquire their vasculature by vessel incorporation, not vessel ingrowth," Journal of Pathology, vol. 151, no. 4, pp. 323-332, 1987.

[13] D. R. Senger, S. J. Galli, A. M. Dvorak, C. A. Perruzzi, V. Susan Harvey, and H. F. Dvorak, "Tumor cells secrete a vascular permeability factor that promotes accumulation of ascites fluid," Science, vol. 219, no. 4587, pp. 983-985, 1983.
[14] D. W. Leung, G. Cachianes, W. J. Kuang, D. V. Goeddel, and N. Ferrara, "Vascular endothelial growth factor is a secreted angiogenic mitogen," Science, vol. 246, no. 4935, pp. 13061309, 1989.

[15] S. A. Eccles and D. R. Welch, "Metastasis: recent discoveries and novel treatment strategies," The Lancet, vol. 369, no. 9574, pp. 1742-1757, 2007.

[16] P. S. Steeg, "Tumor metastasis: mechanistic insights and clinical challenges," Nature Medicine, vol. 12, no. 8, pp. 895904, 2006.

[17] R. N. Kaplan, B. Psaila, and D. Lyden, "Bone marrow cells in the "pre-metastatic niche": within bone and beyond," Cancer and Metastasis Reviews, vol. 25, no. 4, pp. 521-529, 2006.

[18] K. Danø, P. A. Andreasen, J. Grøndahl-Hansen, P. Kristensen, L. S. Nielsen, and L. Skriver, "Plasminogen activators, tissue degradation, and cancer," Advances in Cancer Research, vol. 44, pp. 139-266, 1985.

[19] S. Georges, C. Ruiz Velasco, V. Trichet, Y. Fortun, D. Heymann, and M. Padrines, "Proteases and bone remodelling," Cytokine and Growth Factor Reviews, vol. 20, no. 1, pp. 2941, 2009 .

[20] G. Bergers, R. Brekken, G. McMahon et al., "Matrix metalloproteinase- 9 triggers the angiogenic switch during carcinogenesis," Nature Cell Biology, vol. 2, no. 10, pp. 737-744, 2000.

[21] R. V. Iozzo, J. J. Zoeller, and A. Nyström, "Basement membrane proteoglycans: modulators par excellence of cancer growth and angiogenesis," Molecules and Cells, vol. 27, no. 5, pp. 503-513, 2009.

[22] Y. H. Lee, T. Tokunaga, Y. Oshika et al., "Cell-retained isoforms of vascular endothelial growth factor (VEGF) are correlated with poor prognosis in osteosarcoma," European Journal of Cancer, vol. 35, no. 7, pp. 1089-1093, 1999.

[23] M. Kaya, T. Wada, T. Akatsuka et al., "Vascular endothelial growth factor expression in untreated osteosarcoma is predictive of pulmonary metastasis and poor prognosis," Clinical Cancer Research, vol. 6, no. 2, pp. 572-577, 2000.

[24] A. Franchi, L. Arganini, G. Baroni et al., "Expression of transforming growth factor $\beta$ isoforms in osteosarcoma variants: association of TGF $\beta 1$ with high-grade osteosarcomas," Journal of Pathology, vol. 185, no. 3, pp. 284-289, 1998.

[25] K. Scotlandi, P. Picci, and H. Kovar, "Targeted therapies in bone sarcomas," Current Cancer Drug Targets, vol. 9, no. 7, pp. 843-853, 2009.

[26] A. Abdeen, A. J. Chou, J. H. Healey et al., "Correlation between clinical outcome and growth factor pathway expression in osteogenic sarcoma," Cancer, vol. 115, no. 22, pp. 5243-5250, 2009.

[27] E. Mantadakis, G. Kim, J. Reisch et al., "Lack of prognostic significance of intratumoral angiogenesis in nonmetastatic osteosarcoma," Journal of Pediatric Hematology/Oncology, vol. 23, no. 5, pp. 286-289, 2001.

[28] D. Mikulic, I. Ilić, M. Ćepulić et al., "Tumor angiogenesis and outcome in osteosarcoma," Pediatric Hematology and Oncology, vol. 21, no. 7, pp. 611-619, 2004.

[29] M. Kreuter, R. Bieker, S. S. Bielaek et al., "Prognostic relevance of increased angiogenesis in osteosarcoma," Clinical Cancer Research, vol. 10, no. 24, pp. 8531-8537, 2004.

[30] M. S. O’Reilly, L. Holmgren, Y. Shing et al., "Angiostatin: a novel angiogenesis inhibitor that mediates the suppression of metastases by a Lewis lung carcinoma," Cell, vol. 79, no. 2, pp. 315-328, 1994. 
[31] M. S. O'Reilly, T. Boehm, Y. Shing et al., "Endostatin: an endogenous inhibitor of angiogenesis and tumor growth," Cell, vol. 88, no. 2, pp. 277-285, 1997.

[32] M. Dhanabal, R. Volk, R. Ramchandran, M. Simons, and V. P. Sukhatme, "Cloning, expression, and in vitro activity of human endostatin," Biochemical and Biophysical Research Communications, vol. 258, no. 2, pp. 345-352, 1999.

[33] P. Blezinger, J. Wang, M. Gondo et al., "Systemic inhibition of tumor growth and tumor metastases by intramuscular administration of the endostatin gene," Nature Biotechnology, vol. 17, no. 4, pp. 343-348, 1999.

[34] S. S. Yoon, H. Eto, C. M. Lin et al., "Mouse endostatin inhibits the formation of lung and liver metastases," Cancer Research, vol. 59, no. 24, pp. 6251-6256, 1999.

[35] Y. Yokoyama, M. Dhanabal, A. W. Griffioen, V. P. Sukhatme, and S. Ramakrishnan, "Synergy between angiostatin and endostatin: inhibition of ovarian cancer growth," Cancer Research, vol. 60, no. 8, pp. 2190-2196, 2000.

[36] O. Kisker, C. M. Becker, D. Prox et al., "Continuous administration of endostatin by intraperitoneally implanted osmotic pump improves the efficacy and potency of therapy in a mouse xenograft tumor model," Cancer Research, vol. 61, no. 20, pp. 7669-7674, 2001.

[37] W. Shi, C. Teschendorf, N. Muzyczka, and D. W. Siemann, "Adeno-associated virus-mediated gene transfer of endostatin inhibits angiogenesis and tumor growth in vivo," Cancer Gene Therapy, vol. 9, no. 6, pp. 513-521, 2002.

[38] A. L. Feldman, H. R. Alexander, S. M. Hewitt et al., "Effect of retroviral endostatin gene transfer on subcutaneous and intraperitoneal growth of murine tumors," Journal of the $\mathrm{Na}$ tional Cancer Institute, vol. 93, no. 13, pp. 1014-1020, 2001.

[39] C. Mundhenke, J. P. Thomas, G. Wilding et al., "Tissue examination to monitor antiangiogenic therapy: a phase I clinical trial with endostatin," Clinical Cancer Research, vol. 7, no. 11, pp. 3366-3374, 2001.

[40] J. P. Eder Jr., J. G. Supko, J. W. Clark et al., "Phase I clinical trial of recombinant human endostatin administered as a short intravenous infusion repeated daily," Journal of Clinical Oncology, vol. 20, no. 18, pp. 3772-3784, 2002.

[41] R. S. Herbst, K. R. Hess, H. T. Tran et al., "Phase I study of recombinant human endostatin in patients with advanced solid tumors," Journal of Clinical Oncology, vol. 20, no. 18, pp. 3792-3803, 2002.

[42] J. P. Thomas, R. Z. Arzoomanian, D. Alberti et al., "Phase I pharmacokinetic and pharmacodynamic study of recombinant human endostatin in patients with advanced solid tumors," Journal of Clinical Oncology, vol. 21, no. 2, pp. 223 231, 2003.

[43] F. Deschaseaux, L. Sensébé, and D. Heymann, "Mechanisms of bone repair and regeneration," Trends in Molecular Medicine, vol. 15, no. 9, pp. 417-429, 2009.

[44] K. Bjornland, K. Flatmark, S. Pettersen, A. O. Aaasen, $\varnothing$. Fodstad, and G. M. Mælandsmo, "Matrix metalloproteinases participate in osteosarcoma invasion," Journal of Surgical Research, vol. 127, no. 2, pp. 151-156, 2005.

[45] M. Kansara and D. M. Thomas, "Molecular pathogenesis of osteosarcoma," DNA and Cell Biology, vol. 26, no. 1, pp. 1-18, 2007.

[46] D. G. Fan, J. Y. Dai, J. Tang et al., "Silencing of calpain expression reduces the metastatic potential of human osteosarcoma cells," Cell Biology International, vol. 33, no. 12, pp. 12631267, 2009.
[47] C. M. Díaz-Montero, J. N. Wygant, and B. W. McIntyre, "PI3K/Akt-mediated anoikis resistance of human osteosarcoma cells requires Src activation," European Journal of Cancer, vol. 42, no. 10, pp. 1491-1500, 2006.

[48] P. Hingorani, W. Zhang, R. Gorlick, and E. A. Kolb, "Inhibition of Src phosphorylation alters metastatic potential of osteosarcoma in vitro but not in vivo," Clinical Cancer Research, vol. 15, no. 10, pp. 3416-3422, 2009.

[49] L. C. Kim, L. Song, and E. B. Haura, "Src kinases as therapeutic targets for cancer," Nature Reviews Clinical Oncology, vol. 6, no. 10, pp. 587-595, 2009.

[50] E. M. Rubin, Y. Guo, K. Tu, J. Xie, X. Zi, and B. H. Hoang, "Wnt inhibitory factor 1 decreases tumorigenesis and metastasis in osteosarcoma," Molecular Cancer Therapeutics, vol. 9, no. 3, pp. 731-741, 2010.

[51] Y. Guo, X. Zi, Z. Koontz et al., "Blocking Wnt/LRP5 signaling by a soluble receptor modulates the epithelial to mesenchymal transition and suppresses met and metalloproteinases in osteosarcoma Saos-2 cells," Journal of Orthopaedic Research, vol. 25, no. 7, pp. 964-971, 2007.

[52] F. Engin, T. Bertin, O. Ma et al., "Notch signaling contributes to the pathogenesis of human osteosarcomas," Human Molecular Genetics, vol. 18, no. 8, pp. 1464-1470, 2009.

[53] D. P. M. Hughes, "How the NOTCH pathway contributes to the ability of osteosarcoma cells to metastasize," Cancer Treatment and Research, vol. 152, pp. 479-496, 2009.

[54] M. Tanaka, T. Setoguchi, M. Hirotsu et al., "Inhibition of Notch pathway prevents osteosarcoma growth by cell cycle regulation," British Journal of Cancer, vol. 100, no. 12, pp. 1957-1965, 2009.

[55] P. Zhang, Y. Yang, P. A. Zweidler-McKay, and D. P. M. Hughes, "Critical role of notch signaling in osteosarcoma invasion and metastasis," Clinical Cancer Research, vol. 14, no. 10, pp. 2962-2969, 2008.

[56] Y. Soini, J. Satta, M. Määttä, and H. Autio-Harmainen, "Expression of MMP2, MMP9, MT1-MMP, TIMP1, and TIMP2 mRNA in valvular lesions of the heart," The Journal of Pathology, vol. 194, no. 2, pp. 225-231, 2001.

[57] Y. Kato, T. Yamashita, and M. Ishikawa, "Relationship between expression of matrix metalloproteinase-2 and matrix metalloproteinase- 9 and invasion ability of cervical cancer cells," Oncology reports, vol. 9, no. 3, pp. 565-569, 2002.

[58] P. P. H. Lee, J. J. Hwang, G. Murphy, and M. M. Ip, "Functional significance of MMP-9 in tumor necrosis factorinduced proliferation and branching morphogenesis of mammary epithelial cells," Endocrinology, vol. 141, no. 10, pp. 3764-3773, 2000.

[59] K. Soreide, E. A. Janssen, H. Kömer, and J. P. A. Baak, "Trypsin in colorectal cancer: molecular biological mechanisms of proliferation, invasion, and metastasis," Journal of Pathology, vol. 209, no. 2, pp. 147-156, 2006.

[60] Y. Y. Cheng, L. Huang, K. M. Lee, K. Li, and S. M. Kumta, "Alendronate regulates cell invasion and MMP-2 secretion in human osteosarcoma cell lines," Pediatric Blood and Cancer, vol. 42, no. 5, pp. 410-415, 2004.

[61] P. Heikkila, O. Teronen, M. Y. Hirn et al., "Inhibition of matrix metalloproteinase-14 in osteosarcoma cells by clodronate," Journal of Surgical Research, vol. 111, no. 1, pp. 4552, 2003.

[62] Z. F. Xin, Y. K. Kim, and S. T. Jung, "Risedronate inhibits human osteosarcoma cell invasion," Journal of Experimental and Clinical Cancer Research, vol. 28, no. 1, article 105, 2009. 
[63] D. Heymann, B. Ory, F. Gouin, J. R. Green, and F. Rédini, "Bisphosphonates: new therapeutic agents for the treatment of bone tumors," Trends in Molecular Medicine, vol. 10, no. 7, pp. 337-343, 2004.

[64] G. Moriceau, B. Ory, B. Gobin et al., "Therapeutic approach of primary bone tumours by bisphosphonates," Current Pharmaceutical Design, vol. 16, no. 27, pp. 2981-2987, 2010.

[65] H. J. Cho, T. S. Lee, J. B. Park et al., "Disulfiram suppresses invasive ability of osteosarcoma cells via the inhibition of MMP-2 and MMP-9 expression," Journal of Biochemistry and Molecular Biology, vol. 40, no. 6, pp. 1069-1076, 2007.

[66] C. E. Macsai, B. K. Foster, and C. J. Xian, "Roles of Wnt signalling in bone growth, remodelling, skeletal disorders and fracture repair," Journal of Cellular Physiology, vol. 215, no. 3, pp. 578-587, 2008.

[67] D. A. Glass, P. Bialek, J. D. Ahn et al., "Canonical Wnt signaling in differentiated osteoblasts controls osteoclast differentiation," Developmental Cell, vol. 8, no. 5, pp. 751-764, 2005.

[68] Y. Kawano and R. Kypta, "Secreted antagonists of the Wnt signalling pathway," Journal of Cell Science, vol. 116, no. 13, pp. 2627-2634, 2003.

[69] R. Baron and G. Rawadi, "Minireview: targeting the Wnt/ $\beta$ catenin pathway to regulate bone formation in the adult skeleton," Endocrinology, vol. 148, no. 6, pp. 2635-2643, 2007.

[70] E. Canalis, A. Giustina, and J. P. Bilezikian, "Mechanisms of anabolic therapies for osteoporosis," The New England Journal of Medicine, vol. 357, no. 9, pp. 850-916, 2007.

[71] J. C. Hsieh, L. Kodjabachian, M. L. Rebbert et al., "A new secreted protein that binds to Wnt proteins and inhibits their activites," Nature, vol. 398, no. 6726, pp. 431-436, 1999.

[72] O. Tetsu and F. McCormick, " $\beta$-catenin regulates expression of cyclin D1 in colon carcinoma cells," Nature, vol. 398, no. 6726, pp. 422-426, 1999.

[73] T. C. He, A. B. Sparks, C. Rago et al., "Identification of cMYC as a target of the APC pathway," Science, vol. 281, no. 5382, pp. 1509-1512, 1998.

[74] H. C. Crawford, B. M. Fingleton, L. A. Rudolph-Owen et al., "The metalloproteinase matrilysin is a target of $\beta$-catenin transactivation in intestinal tumors," Oncogene, vol. 18, no. 18 , pp. 2883-2891, 1999.

[75] P. J. Kim, J. Plescia, H. Clevers, E. R. Fearon, and D. C. Altieri, "Survivin and molecular pathogenesis of colorectal cancer," The Lancet, vol. 362, no. 9379, pp. 205-209, 2003.

[76] R. C. Haydon, A. Deyrup, A. Ishikawa et al., "Cytoplasmic and/or nuclear accumulation of the $\beta$-catenin protein is a frequent event in human osteosarcoma," International Journal of Cancer, vol. 102, no. 4, pp. 338-342, 2002.

[77] K. Iwaya, H. Ogawa, M. Kuroda, M. Izumi, T. Ishida, and K. Mukai, "Cytoplasmic and/or nuclear staining of beta-catenin is associated with lung metastasis," Clinical and Experimental Metastasis, vol. 20, no. 6, pp. 525-529, 2003.

[78] K. Iwao, Y. Miyoshi, G. Nawa, H. Yoshikawa, T. Ochi, and Y. Nakamura, "Frequent $\beta$-catenin abnormalities in bone and soft-tissue tumors," Japanese Journal of Cancer Research, vol. 90, no. 2, pp. 205-209, 1999.

[79] B. H. Hoang, T. Kubo, J. H. Healey et al., "Expression of LDL receptor-related protein 5 (LRP5) as a novel marker for disease progression in high-grade osteosarcoma," International Journal of Cancer, vol. 109, no. 1, pp. 106-111, 2004.

[80] B. H. Hoang, T. Kubo, J. H. Healey et al., "Dickkopf 3 inhibits invasion and motility of Saos-2 osteosarcoma cells by modulating the Wnt- $\beta$-catenin pathway," Cancer Research, vol. 64 , no. 8, pp. 2734-2739, 2004.
[81] P. Polakis, "Wnt signaling and cancer," Genes and Development, vol. 14, no. 15, pp. 1837-1851, 2000.

[82] P. C. Leow, Q. Tian, Z. Y. Ong, Z. Yang, and P. L. R. Ee, "Antitumor activity of natural compounds, curcumin and PKF118-310, as Wnt/ $\beta$-catenin antagonists against human osteosarcoma cells," Investigational New Drugs, vol. 28, no. 6, pp. 766-782, 2010.

[83] J. Mazieres, B. He, L. You et al., "Wnt inhibitory factor-1 is silenced by promoter hypermethylation in human lung cancer," Cancer Research, vol. 64, no. 14, pp. 4717-4720, 2004.

[84] Y. C. Lin, L. You, Z. Xu et al., "Wnt signaling activation and WIF-1 silencing in nasopharyngeal cancer cell lines," Biochemical and Biophysical Research Communications, vol. 341, no. 2, pp. 635-640, 2006.

[85] L. Ai, Q. Tao, S. Zhong et al., "Inactivation of Wnt inhibitory factor-1 (WIF1) expression by epigenetic silencing is a common event in breast cancer," Carcinogenesis, vol. 27, no. 7, pp. 1341-1348, 2006.

[86] S. Yamashita, Y. Tsujino, K. Moriguchi, M. Tatematsu, and T. Ushijima, "Chemical genomic screening for methylationsilenced genes in gastric cancer cell lines using 5-aza-2'deoxycytidine treatment and oligonucleotide microarray," Cancer Science, vol. 97, no. 1, pp. 64-71, 2006.

[87] S. Artavanis-Tsakonas, M. D. Rand, and R. J. Lake, "Notch signaling: cell fate control and signal integration in development," Science, vol. 284, no. 5415, pp. 770-776, 1999.

[88] R. Kopan and M. X. Ilagan, "The canonical notch signaling pathway: unfolding the activation mechanism," Cell, vol. 137, no. 2, pp. 216-233, 2009.

[89] T. Iso, L. Kedes, and Y. Hamamori, "HES and HERP families: multiple effectors of the Notch signaling pathway," Journal of Cellular Physiology, vol. 194, no. 3, pp. 237-255, 2003.

[90] M. C. Maa, T. H. Leu, D. J. Mccarley, R. C. Schatzman, and S. J. Parsons, "Potentiation of epidermal growth factor receptor-mediated oncogenesis by c-Src: implications for the etiology of multiple human cancers," Proceedings of the National Academy of Sciences of the United States of America, vol. 92, no. 15, pp. 6981-6985, 1995.

[91] S. Mori, L. Ronnstrand, K. Yokote et al., "Identification of two juxtamembrane autophosphorylation sites in the PGDF $\beta$-receptor; Involvement in the interaction with Src family tyrosine kinases," The EMBO Journal, vol. 12, no. 6, pp. 22572264, 1993.

[92] M. P. Playford and M. D. Schaller, "The interplay between Src and integrins in normal and tumor biology," Oncogene, vol. 23, no. 48, pp. 7928-7946, 2004.

[93] M. Talpaz, N. P. Shah, H. Kantarjian et al., "Dasatinib in imatinib-resistant Philadelphia chromosome-positive leukemias," The New England Journal of Medicine, vol. 354, no. 24, pp. 2531-2541, 2006.

[94] F. M. Johnson, B. Saigal, M. Talpaz, and N. J. Donato, "Dasatinib (BMS-354825) tyrosine kinase inhibitor suppresses invasion and induces cell cycle arrest and apoptosis of head and neck squamous cell carcinoma and non-small cell lung cancer cells," Clinical Cancer Research, vol. 11, no. 19, part 1, pp. 6924-6932, 2005.

[95] M. M. Schittenhelm, S. Shiraga, A. Schroeder et al., "Dasatinib (BMS-354825), a dual SRC/ABL kinase inhibitor, inhibits the kinase activity of wild-type, juxtamembrane, and activation loop mutant KIT isoforms associated with human malignancies," Cancer Research, vol. 66, no. 1, pp. 473-481, 2006.

[96] A. C. Shor, E. A. Keschman, F. Y. Lee et al., "Dasatinib inhibits migration and invasion in diverse human sarcoma cell lines 
and induces apoptosis in bone sarcoma cells dependent on Src kinase for survival," Cancer Research, vol. 67, no. 6, pp. 2800-2808, 2007.

[97] L. B. Owen-Schaub, K. L. Van Golen, L. L. Hill, and J. E. Price, "Fas and Fas ligand interactions suppress melanoma lung metastasis," Journal of Experimental Medicine, vol. 188, no. 9, pp. 1717-1723, 1998.

[98] T. J. Sayers, A. D. Brooks, J. K. Lee et al., "Molecular mechanisms of immune-mediated lysis of murine renal cancer: differential contributions of perforin-dependent versus fasmediated pathways in lysis by NK and T cells," Journal of Immunology, vol. 161, no. 8, pp. 3957-3965, 1998.

[99] J. K. Lee, T. J. Sayers, A. D. Brooks et al., "IFN- $\gamma$-dependent delay of in vivo tumor progression by Fas overexpression on murine renal cancer cells," Journal of Immunology, vol. 164, no. 1, pp. 231-239, 2000.

[100] N. Gordon, C. A. Arndt, D. S. Hawkins et al., "Fas expression in lung metastasis from osteosarcoma patients," Journal of Pediatric Hematology/Oncology, vol. 27, no. 11, pp. 611-615, 2005.

[101] L. L. Worth, E. A. Lafleur, S. F. Jia, and E. S. Kleinerman, "Fas expression inversely correlates with metastatic potential in osteosarcoma cells," Oncology Reports, vol. 9, no. 4, pp. 823827, 2002.

[102] M. E. Peter, R. C. Budd, J. Desbarats et al., "The CD95 receptor: apoptosis revisited," Cell, vol. 129, no. 3, pp. 447450, 2007.

[103] L. Chen, S. M. Park, A. V. Tumanov et al., "CD95 promotes tumour growth," Nature, vol. 465, no. 7297, pp. 492-496, 2010.

[104] A. Strasser, P. J. Jost, and S. Nagata, "The many roles of FAS receptor signaling in the immune system," Immunity, vol. 30, no. 2, pp. 180-192, 2009.

[105] F. H. Igney and P. H. Krammer, "Death and anti-death: tumour resistance to apoptosis," Nature Reviews Cancer, vol. 2, no. 4, pp. 277-288, 2002.

[106] R. Gorlick, P. Anderson, I. Andrulis et al., "Biology of ghildhood osteogenic sarcoma and potential targets for therapeutic development: meeting summary," Clinical Cancer Research, vol. 9, no. 15, pp. 5442-5453, 2003.

[107] N. V. Koshkina, C. Khanna, A. Mendoza, H. Guan, L. DeLauter, and E. S. Kleinerman, "Fas-negative osteosarcoma tumor cells are selected during metastasis to the lungs: the role of the fas pathwayin the metastatic process of osteosarcoma," Molecular Cancer Research, vol. 5, no. 10, pp. 991-999, 2007.

[108] E. A. Lafleur, S. F. Jia, L. L. Worth, Z. Zhou, L. B. OwenSchaub, and E. S. Kleinerman, "Interleukin (IL)-12 and IL-12 gene transfer up-regulate Fas expression in human osteosarcoma and breast cancer cells," Cancer Research, vol. 61, no. 10, pp. 4066-4071, 2001.

[109] E. A. Lafleur, N. V. Koshkina, J. Stewart et al., "Increased Fas expression reduces the metastatic potential of human osteosarcoma cells," Clinical Cancer Research, vol. 10, no. 23, pp. 8114-8119, 2004.

[110] Z. Zhou, E. A. Lafleur, N. V. Koshkina, L. L. Worth, M. S. Lester, and E. S. Kleinerman, "Interleukin-12 up-regulates Fas expression in human osteosarcoma and Ewing's sarcoma cells by enhancing its promoter activity," Molecular Cancer Research, vol. 3, no. 12, pp. 685-691, 2005.

[111] X. Duan, S. F. Jia, N. Koshkina, and E. S. Kleinerman, "Intranasal interleukin-12 gene therapy enhanced the activity of ifosfamide against osteosarcoma lung metastases," Cancer, vol. 106, no. 6, pp. 1382-1388, 2006.
[112] K. Mori, K. Ando, and D. Heymann, "Liposomal muramyl tripeptide phosphatidyl ethanolamine: a safe and effective agent against osteosarcoma pulmonary metastases," Expert Review of Anticancer Therapy, vol. 8, no. 2, pp. 151-159, 2008.

[113] S. Lebel-Binay, A. Berger, F. Zinzindohoué et al., "Interleukin-18: biological properties and clinical implications," European Cytokine Network, vol. 11, no. 1, pp. 15-25, 2000.

[114] J. Golab, "Interleukin 18-Interferon $\gamma$ inducing factor-a novel player in tumour immunotherapy?" Cytokine, vol. 12, no. 4, pp. 332-338, 2000.

[115] R. Cao, J. Farnebo, M. Kurimoto, and Y. Cao, "Interleukin-18 acts as an angiogenesis and tumor suppressor," The FASEB Journal, vol. 13, no. 15, pp. 2195-2202, 1999.

[116] T. Ohtsuki, M. J. Micallef, K. Kohno, T. Tanimoto, M. Ikeda, and M. Kurimoto, "Interleukin 18 enhances Fas ligand expression and induces apoptosis in Fas-expressing human myelomonocytic KG-1 cells," Anticancer Research, vol. 17, no. 5, pp. 3253-3258, 1997.

[117] Y. Nakamura, N. Yamada, H. Ohyama et al., "Effect of interleukin-18 on metastasis of mouse osteosarcoma cells," Cancer Immunology, Immunotherapy, vol. 55, no. 9, pp. 1151-1158, 2006.

[118] N. Yamada, M. Hata, H. Ohyama et al., "Immunotherapy with interleukin-18 in combination with preoperative chemotherapy with ifosfamide effectively inhibits postoperative progression of pulmonary metastases in a mouse osteosarcoma model," Tumor Biology, vol. 30, no. 4, pp. 176184, 2009.

[119] N. Boudreau, C. J. Sympson, Z. Werb, and M. J. Bissell, "Suppression of ICE and apoptosis in mammary epithelial cells by extracellular matrix," Science, vol. 267, no. 5199, pp. 891-893, 1995.

[120] J. Grossmann, K. Walther, M. Artinger, S. Kiessling, and J. Schölmerich, "Apoptotic signaling during initiation of detachment-induced apoptosis ("anoikis") of primary human intestinal epithelial cells," Cell Growth and Differentiation, vol. 12, no. 3, pp. 147-155, 2001.

[121] S. M. Frisch and R. A. Screaton, "Anoikis mechanisms," Current Opinion in Cell Biology, vol. 13, no. 5, pp. 555-562, 2001.

[122] C. M. Diaz-Montero and B. W. McIntyre, "Acquisition of anoikis resistance in human osteosarcoma cells," European Journal of Cancer, vol. 39, no. 16, pp. 2395-2402, 2003.

[123] L. A. Liotta and E. Kohn, "Anoikis: cancer and the homeless cell," Nature, vol. 430, no. 7003, pp. 973-974, 2004.

[124] P. Mehlen and A. Puisieux, "Metastasis: a question of life or death," Nature Reviews Cancer, vol. 6, no. 6, pp. 449-458, 2006.

[125] L. Trusolino, A. Bertotti, and P. M. Comoglio, "A signaling adapter function for $\alpha 6 \beta 4$ integrin in the control of HGFdependent invasive growth," Cell, vol. 107, no. 5, pp. 643-654, 2001.

[126] S. N. Nikolopoulos, P. Blaikie, T. Yoshioka, W. Guo, and F. G. Giancotti, "Integrin $\beta 4$ signaling promotes tumor angiogenesis," Cancer Cell, vol. 6, no. 5, pp. 471-483, 2004.

[127] W. Guo, Y. Pylayeva, A. Pepe et al., " $\beta 4$ integrin amplifies ErbB2 signaling to promote mammary tumorigenesis," Cell, vol. 126, no. 3, pp. 489-502, 2006.

[128] X. Wan, S. Y. Kim, L. M. Guenther et al., "Beta4 integrin promotes osteosarcoma metastasis and interacts with ezrin," Oncogene, vol. 28, no. 38, pp. 3401-3411, 2009.

[129] P. Chiarugi and E. Giannoni, "Anoikis: a necessary death program for anchorage-dependent cells," Biochemical Pharmacology, vol. 76, no. 11, pp. 1352-1364, 2008. 
[130] S. M. Janes and F. M. Watt, "Switch from $\alpha \mathrm{v} \beta 5$ to $\alpha \mathrm{v} \beta 6$ integrin expression protects squamous cell carcinomas from anoikis," Journal of Cell Biology, vol. 166, no. 3, pp. 419-431, 2004.

[131] R. V. Stan, "Structure of caveolae," Biochimica et Biophysica Acta, vol. 1746, no. 3, pp. 334-348, 2005.

[132] K. G. Rothberg, J. E. Heuser, W. C. Donzell, Y. S. Ying, J. R. Glenney, and R. G. W. Anderson, "Caveolin, a protein component of caveolae membrane coats," Cell, vol. 68, no. 4, pp. 673-682, 1992.

[133] K. R. Solomon, T. E. Danciu, L. D. Adolphson, L. E. Hecht, and P. V. Hauschka, "Caveolin-enriched membrane signaling complexes in human and murine osteoblasts," Journal of Bone and Mineral Research, vol. 15, no. 12, pp. 2380-2390, 2000.

[134] L. Cantiani, M. C. Manara, C. Zucchini et al., "Caveolin-1 reduces osteosarcoma metastases by inhibiting c-Src activity and met signaling," Cancer Research, vol. 67, no. 16, pp. 76757685, 2007.

[135] A. B. Al-Mehdi, K. Tozawa, A. B. Fisher, L. Shientag, A. Lee, and R. J. Muschel, "Intravascular origin of metastasis from the proliferation of endothelium-attached tumor cells: a new model for metastasis," Nature Medicine, vol. 6, no. 1, pp. 100$102,2000$.

[136] G. M. Jeffree, C. H. Price, and H. A. Sissons, "The metastatic patterns of osteosarcoma," British Journal of Cancer, vol. 32, no. 1, pp. 87-107, 1975.

[137] F. Lin, S.-E. Zheng, Z. Shen et al., "Relationships between levels of CXCR4 and VEGF and blood-borne metastasis and survival in patients with osteosarcoma," Medical Oncology, vol. 28, no. 2, pp. 649-653, 2011.

[138] C. Laverdiere, B. H. Hoang, R. Yang et al., "Messenger RNA expression levels of CXCR4 correlate with metastatic behavior and outcome in patients with osteosarcoma," Clinical Cancer Research, vol. 11, no. 7, pp. 2561-2567, 2005.

[139] C. Y. Huang, C. Y. Lee, M. Y. Chen et al., "Stromal cell-derived factor-1/CXCR4 enhanced motility of human osteosarcoma cells involves MEK1/2, ERK and NF- $\kappa$ B-dependent pathways," Journal of Cellular Physiology, vol. 221, no. 1, pp. 204212, 2009.

[140] P. M. Murphy, "Chemokines and the molecular basis of cancer metastasis," The New England Journal of Medicine, vol. 345, no. 11, pp. 833-835, 2001.

[141] A. Müller, B. Homey, H. Soto et al., "Involvement of chemokine receptors in breast cancer metastasis," Nature, vol. 410, no. 6824 , pp. 50-56, 2001.

[142] T. Murakami, W. Maki, A. R. Cardones et al., "Expression of CXC chemokine receptor- 4 enhances the pulmonary metastatic potential of murine B16 melanoma cells," Cancer Research, vol. 62, no. 24, pp. 7328-7334, 2002.

[143] C. J. Scotton, J. L. Wilson, K. Scott et al., "Multiple actions of the chemokine CXCL12 on epithelial tumor cells in human ovarian cancer," Cancer Research, vol. 62, no. 20, pp. 59305938, 2002.

[144] E. Pradelli, B. Karimdjee-Soilihi, J. F. Michiels et al., "Antagonism of chemokine receptor CXCR3 inhibits osteosarcoma metastasis to lungs," International Journal of Cancer, vol. 125, no. 11, pp. 2586-2594, 2009.

[145] F. de Nigris, R. Rossiello, C. Schiano et al., "Deletion of Yin Yang 1 protein in osteosarcoma cells on cell invasion and CXCR4/angiogenesis and metastasis," Cancer Research, vol. 68, no. 6, pp. 1797-1808, 2008.

[146] M. M. Robledo, R. A. Bartolomé, N. Longo et al., "Expression of functional chemokine receptors CXCR3 and CXCR4 on human melanoma cells," Journal of Biological Chemistry, vol. 276, no. 48, pp. 45098-45105, 2001.

[147] D. Jones, R. J. Benjamin, A. Shahsafaei, and D. M. Dorfman, "The chemokine receptor CXCR3 is expressed in a subset of $\mathrm{B}$-cell lymphomas and is a marker of B-cell chronic lymphocytic leukemia," Blood, vol. 95, no. 2, pp. 627-632, 2000.

[148] L. Goldberg-Bittman, E. Neumark, O. Sagi-Assif et al., "The expression of the chemokine receptor CXCR3 and its ligand, CXCL10, in human breast adenocarcinoma cell lines," Immunology Letters, vol. 92, no. 1-2, pp. 171-178, 2004.

[149] P. Mangeat, C. Roy, and M. Martin, "ERM proteins in cell adhesion and membrane dynamics," Trends in Cell Biology, vol. 9, no. 5, pp. 187-192, 1999.

[150] M. Hirao, N. Sato, T. Kondo et al., "Regulation mechanism of ERM (ezrin/radixin/moesin) protein/plasma membrane association: possible involvement of phosphatidylinositol turnover and rho-dependent signaling pathway," Journal of Cell Biology, vol. 135, no. 1, pp. 37-51, 1996.

[151] A. Gautreau, P. Poullet, D. Louvard, and M. Arpin, "Ezrin, a plasma membrane-microfilament linker, signals cell survival through the phosphatidylinositol 3-kinase/Akt pathway," Proceedings of the National Academy of Sciences of the United States of America, vol. 96, no. 13, pp. 7300-7305, 1999.

[152] K. W. Hunter, "Ezrin, a key component in tumor metastasis," Trends in Molecular Medicine, vol. 10, no. 5, pp. 201-204, 2004.

[153] S. Ilmonen, A. Vaheri, S. Asko-Seljavaara, and O. Carpen, "Ezrin in primary cutaneous melanoma," Modern Pathology, vol. 18, no. 4, pp. 503-510, 2005.

[154] W. H. Weng, J. Åhlén, K. Åström, W. O. Lui, and C. Larsson, "Prognostic impact of immunohistochemical expression of ezrin in highly malignant soft tissue sarcomas," Clinical Cancer Research, vol. 11, no. 17, pp. 6198-6204, 2005.

[155] C. Khanna, X. Wan, S. Bose et al., "The membrane-cytoskeleton linker ezrin is necessary for osteosarcoma metastasis," Nature Medicine, vol. 10, no. 2, pp. 182-186, 2004.

[156] L. Ren, S. H. Hong, J. Cassavaugh et al., "The actin-cytoskeleton linker protein ezrin is regulated during osteosarcoma metastasis by PKC," Oncogene, vol. 28, no. 6, pp. 792-802, 2009.

[157] C. Khanna, J. Khan, P. Nguyen et al., "Metastasis-associated differences in gene expression in a murine model of osteosarcoma," Cancer Research, vol. 61, no. 9, pp. 3750-3759, 2001.

[158] S. Ikeda, H. Sumii, K. Akiyama et al., "Amplification of both c-myc and c-raf-1 oncogenes in a human osteosarcoma," Japanese Journal of Cancer Research, vol. 80, no. 1, pp. 6-9, 1989.

[159] S. M. Wilhelm, C. Carter, L. Tang et al., "BAY 43-9006 exhibits broad spectrum oral antitumor activity and targets the RAF/MEK/ERK pathway and receptor tyrosine kinases involved in tumor progression and angiogenesis," Cancer Research, vol. 64, no. 19, pp. 7099-7109, 2004.

[160] Y. Pignochino, G. Grignani, G. Cavalloni et al., "Sorafenib blocks tumour growth, angiogenesis and metastatic potential in preclinical models of osteosarcoma through a mechanism potentially involving the inhibition of ERK1/2, MCL-1 and ezrin pathways," Molecular Cancer, vol. 8, article 118, 2009.

[161] V. Hesse, G. Jahreis, H. Schambach et al., "Insulin-like growth factor I correlations to changes of the hormonal status in puberty and age," Experimental and Clinical Endocrinology, vol. 102, no. 4, pp. 289-298, 1994.

[162] N. Kawai, S. Kanzaki, S. Takano-Watou et al., "Serum free insulin-like growth factor I (IGF-I), total IGF-I, and IGF- 
binding protein-3 concentrations in normal children and children with growth hormone deficiency," Journal of Clinical Endocrinology and Metabolism, vol. 84, no. 1, pp. 82-89, 1999.

[163] N. Herzlieb, B. W. Gallaher, A. Berthold, R. Hille, and W. Kiess, "Insulin-like growth factor-I inhibits the progression of human U-2 OS osteosarcoma cells towards programmed cell death through interaction with the IGF-I receptor," Cellular and Molecular Biology, vol. 46, no. 1, pp. 71-77, 2000.

[164] C. C. Kappel, M. C. Velez-Yanguas, S. Hirschfeld, and L. J. Helman, "Human osteosarcoma cell lines are dependent on insulin-like growth factor I for in vitro growth," Cancer Research, vol. 54, no. 10, pp. 2803-2807, 1994.

[165] M. Pollak, A. W. Sem, M. Richard, E. Tetenes, and R. Bell, "Inhibition of metastatic behavior of murine osteosarcoma by hypophysectomy," Journal of the National Cancer Institute, vol. 84, no. 12, pp. 966-971, 1992.

[166] P. J. Mansky, D. J. Liewehr, S. M. Steinberg et al., "Treatment of metastatic osteosarcoma with the somatostatin analog oncoLar: significant reduction of insulin-like growth factor-1 serum levels," Journal of Pediatric Hematology/Oncology, vol. 24, no. 6, pp. 440-446, 2002.

[167] C. Khanna, J. Prehn, D. Hayden et al., "A randomized controlled trial of octreotide pamoate long-acting release and carboplatin versus carboplatin alone in dogs with naturally occurring osteosarcoma: evaluation of insulin-like growth factor suppression and chemotherapy," Clinical Cancer Research, vol. 8, no. 7, pp. 2406-2412, 2002.

[168] Y. H. Wang, Z. X. Wang, Y. Qiu et al., "Lentivirusmediated RNAi knockdown of insulin-like growth factor1 receptor inhibits growth, reduces invasion, and enhances radiosensitivity in human osteosarcoma cells," Molecular and Cellular Biochemistry, vol. 327, no. 1-2, pp. 257-266, 2009.

[169] Y. H. Wang, J. Xiong, S. F. Wang et al., "Lentivirus-mediated shRNA targeting insulin-like growth factor-1 receptor (IGF1R) enhances chemosensitivity of osteosarcoma cells in vitro and in vivo," Molecular and Cellular Biochemistry, vol. 341, no. 1-2, pp. 225-233, 2010.

[170] E. A. Kolb, R. Gorlick, P. J. Houghton et al., "Initial testing (stage 1) of a monoclonal antibody ( $\mathrm{SCH} 717454$ ) against the IGF-1 receptor by the pediatric preclinical testing program," Pediatric Blood and Cancer, vol. 50, no. 6, pp. 1190-1197, 2008.

[171] E. A. Kolb, D. Kamara, W. Zhang et al., "R1507, a fully human monoclonal antibody targeting IGF-1R, is effective alone and in combination with rapamycin in inhibiting growth of osteosarcoma xenografts," Pediatric Blood and Cancer, vol. 55, no. 1, pp. 67-75, 2010.

[172] Y. H. Wang, X. D. Han, Y. Qiu et al., "Increased expression of insulin-like growth factor-1 receptor is correlated with tumor metastasis and prognosis in patients with osteosarcoma," Journal of Surgical Oncology, vol. 105, no. 3, pp. 235-243, 2012.

[173] K. Pantel and R. H. Brakenhoff, "Dissecting the metastatic cascade," Nature Reviews Cancer, vol. 4, no. 6, pp. 448-456, 2004.

[174] J. A. Aguirre-Ghiso, "Models, mechanisms and clinical evidence for cancer dormancy," Nature Reviews Cancer, vol. 7, no. 11, pp. 834-846, 2007.

[175] G. N. Naumov, J. L. Townson, I. C. MacDonald et al., "Ineffectiveness of doxorubicin treatment on solitary dormant mammary carcinoma cells or late-developing metastases," Breast Cancer Research and Treatment, vol. 82, no. 3, pp. 199206, 2003.
[176] L. Holmgren, M. S. O’Reilly, and J. Folkman, "Dormancy of micrometastases: balanced proliferation and apoptosis in the presence of angiogenesis suppression," Nature Medicine, vol. 1, no. 2, pp. 149-153, 1995.

[177] H. Wikman, R. Vessella, and K. Pantel, "Cancer micrometastasis and tumour dormancy," APMIS, vol. 116, no. 7-8, pp. 754-770, 2008.

[178] G. N. Naumov, E. Bender, D. Zurakowski et al., "A model of human tumor dormancy: an angiogenic switch from the nonangiogenic phenotype," Journal of the National Cancer Institute, vol. 98, no. 5, pp. 316-325, 2006.

[179] Y. Cao, M. S. O’Reilly, B. Marshall, E. Flynn, R. W. Ji, and J. Folkman, "Expression of angiostatin cDNA in a murine fibrosarcoma suppresses primary tumor growth and produces long-term dormancy of metastases," Journal of Clinical Investigation, vol. 101, no. 5, pp. 1055-1063, 1998.

[180] E. Favaro, A. Amadori, and S. Indraccolo, "Cellular interactions in the vascular niche: implications in the regulation of tumor dormancy," APMIS, vol. 116, no. 7-8, pp. 648-659, 2008.

[181] D. Barkan, J. E. Green, and A. F. Chambers, "Extracellular matrix: a gatekeeper in the transition from dormancy to metastatic growth," European Journal of Cancer, vol. 46, no. 7, pp. 1181-1188, 2010.

[182] C. M. Koebel, W. Vermi, J. B. Swann et al., "Adaptive immunity maintains occult cancer in an equilibrium state," Nature, vol. 450, no. 7171, pp. 903-907, 2007. 


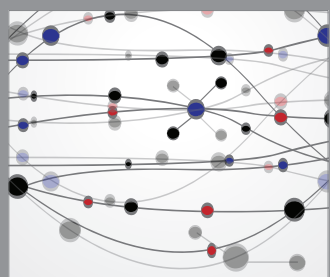

The Scientific World Journal
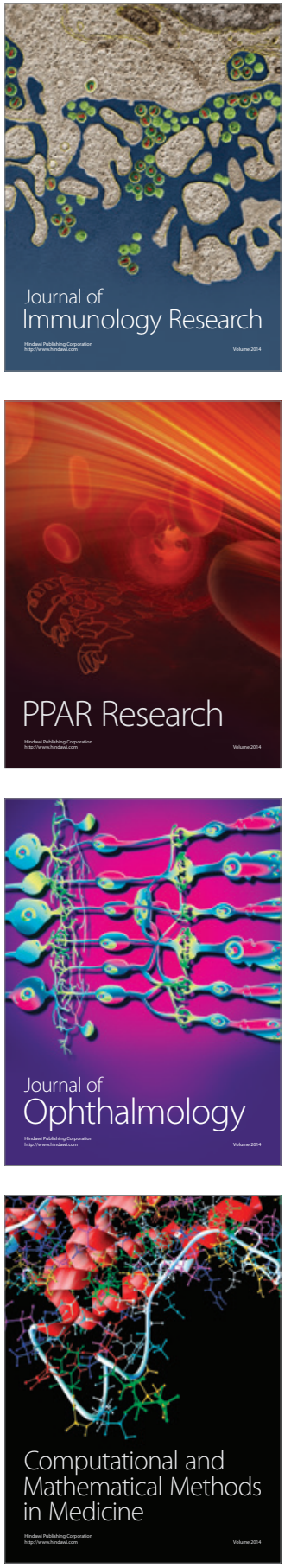

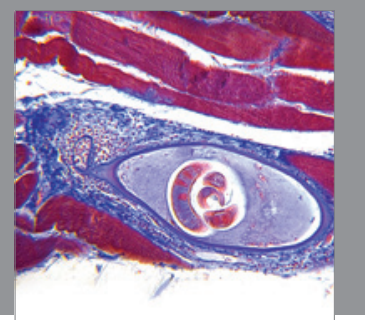

Gastroenterology

Research and Practice
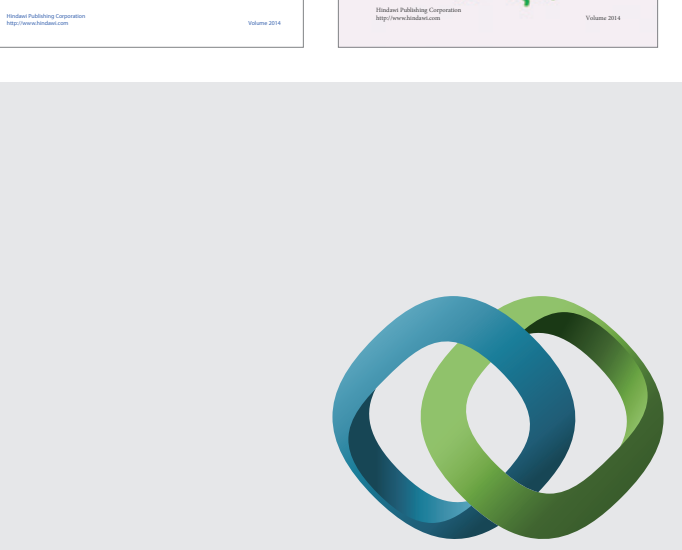

\section{Hindawi}

Submit your manuscripts at

http://www.hindawi.com
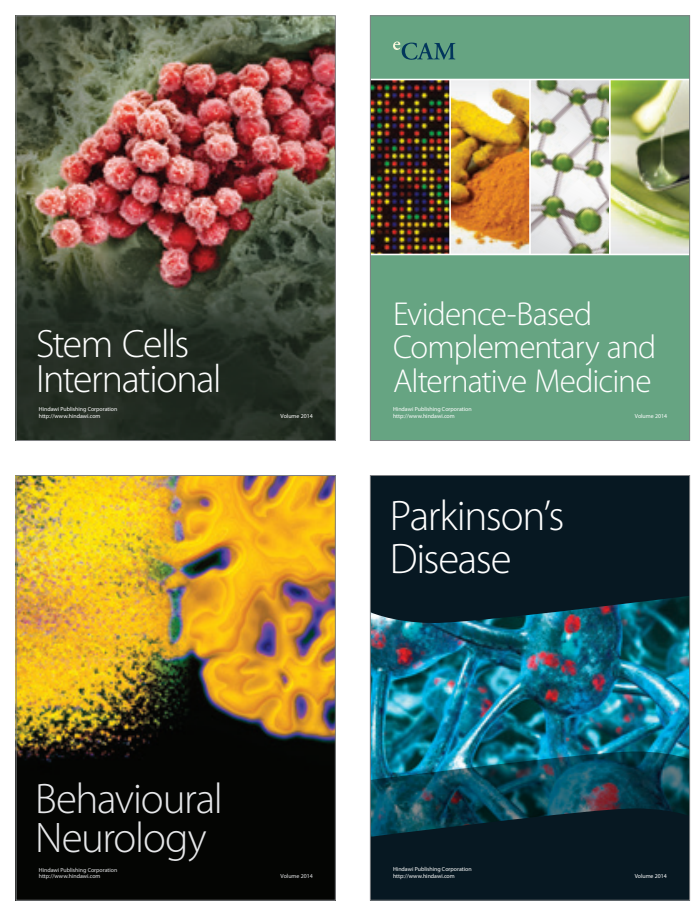

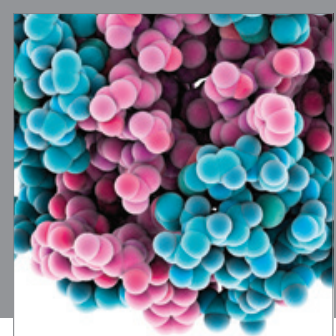

Journal of
Diabetes Research

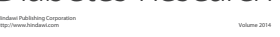

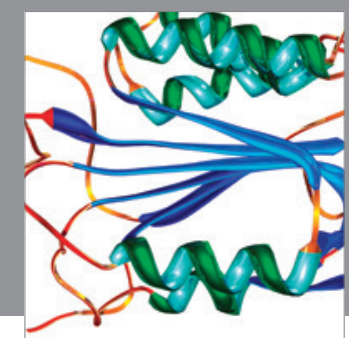

Disease Markers
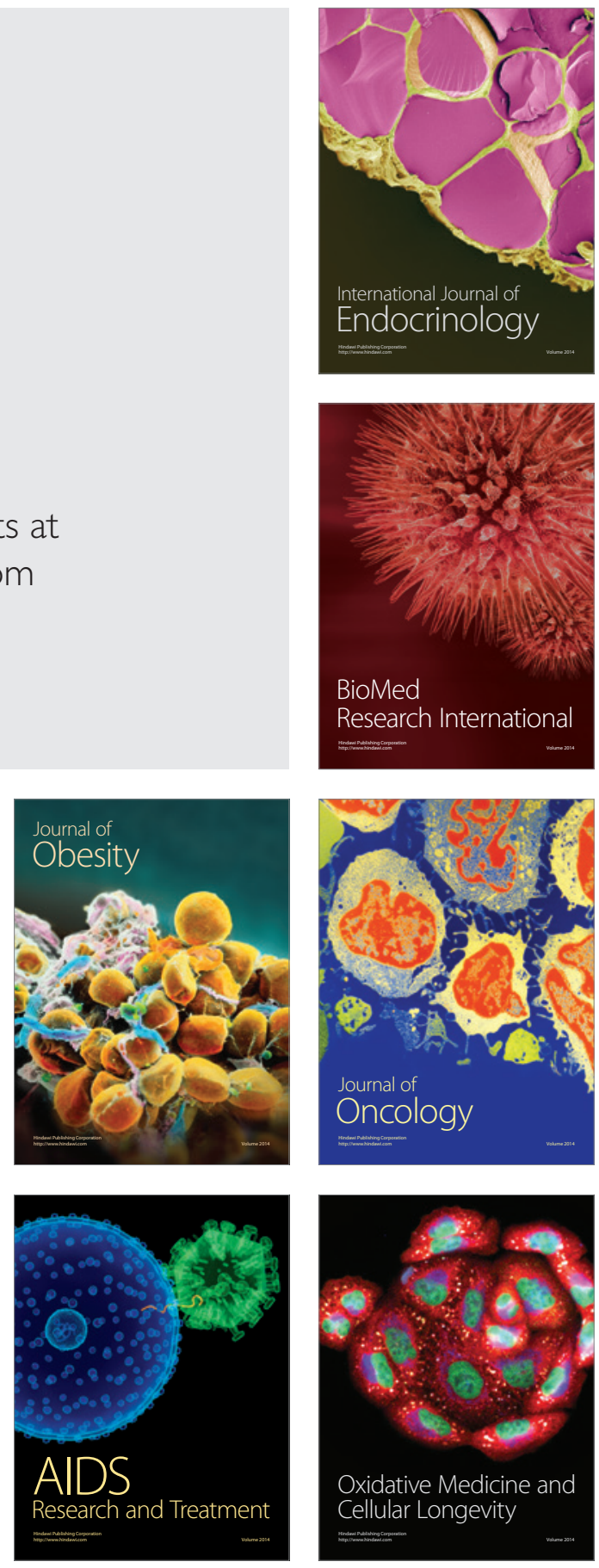